\title{
Erratum to: Soil and fertilizer constraints to wheat and rice production and their alleviation in six intensive cereal-based farming systems of the Indian sub-continent and China
}

\author{
Nianjie Liu • Xiaoyun Li $\cdot$ Stephen R. Waddington
}

Published online: 21 October 2014

(C) Springer Science+Business Media Dordrecht and International Society for Plant Pathology 2014

Erratum to: Food Security (2014)

DOI 10.1007/s12571-014-0377-x

The published article unfortunately contains errors in figures 2, 3, 4 and 5 images. The succeeding pages are the correct versions of said figures.

The online version of the original article can be found at http://dx.doi.org/ 10.1007/s12571-014-0377-x.

N. Liu $\cdot$ X. Li $(\bowtie)$

College of Economics and Management, Huazhong Agricultural

University, Wuhan, Hubei 430070, China

e-mail: lixiaoyun@mail.hzau.edu.cn

N. Liu

e-mail: liunianjie@webmail.hzau.edu.cn

S. R. Waddington

Apartado Postal 4-205, Colonia Chapultepec,

Cuernavaca, CP 62451, Mexico

e-mail: srwaddington@gmail.com 


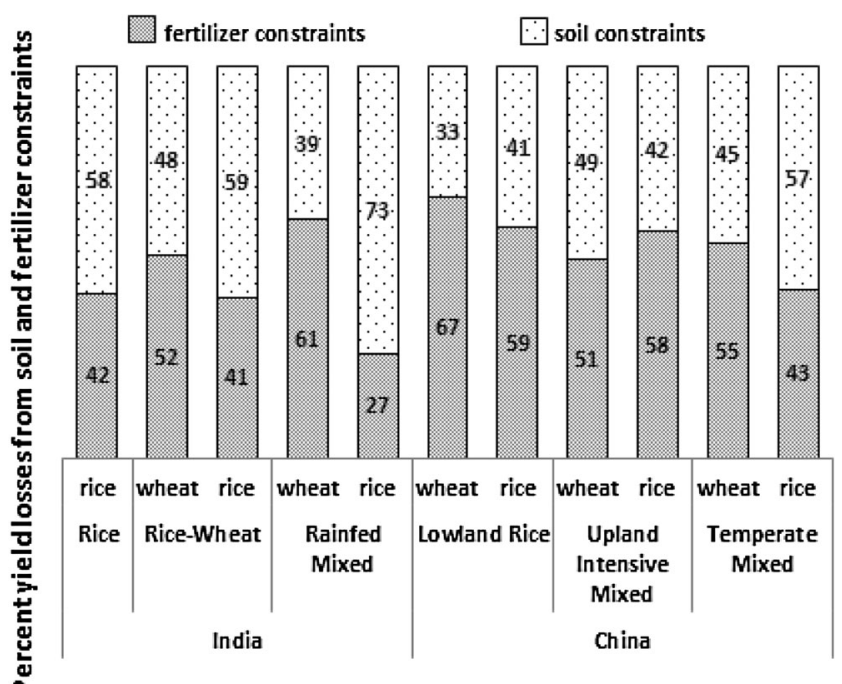

Fig. 2 Relative importance of soil and fertilizer constraints for wheat and rice in six farming systems in China and Indian sub-continent, 2008-09

$\square$ CM 圈PSE $\because$ VG
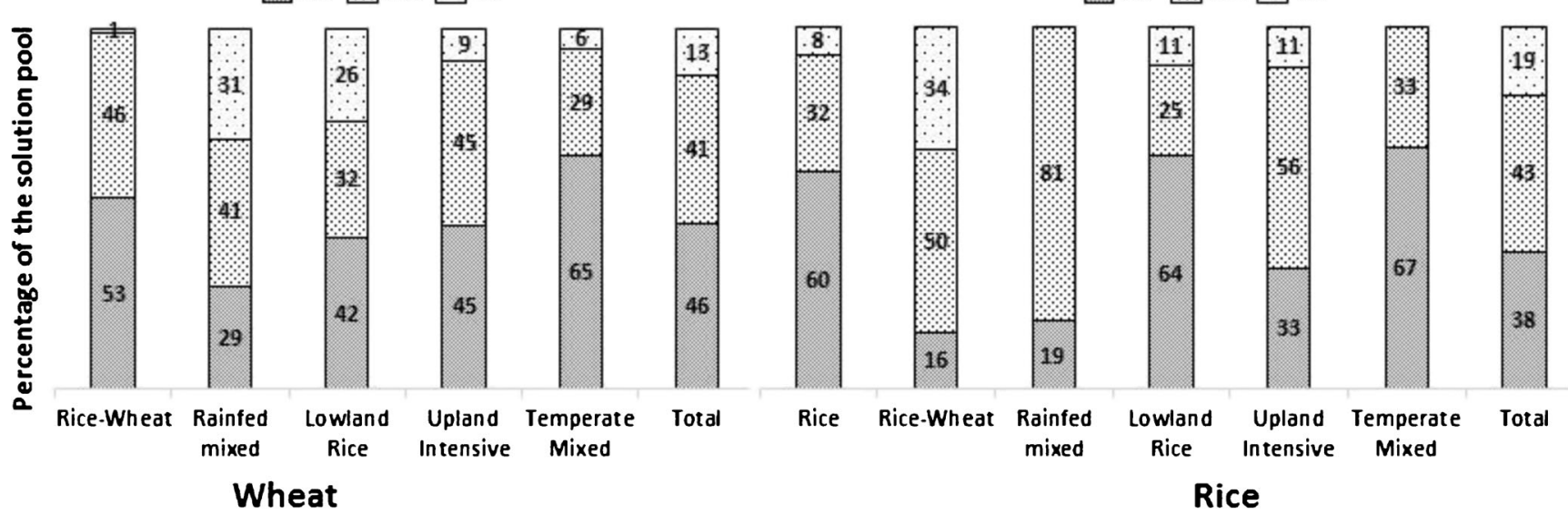

Fig. 3 The percent of crop management (CM), policy/socioecomomic (PSE), and variety/germplasm (VG) solutions to constraints identified by expert informants for wheat and rice in China and the Indian sub-continent, 2008-09 


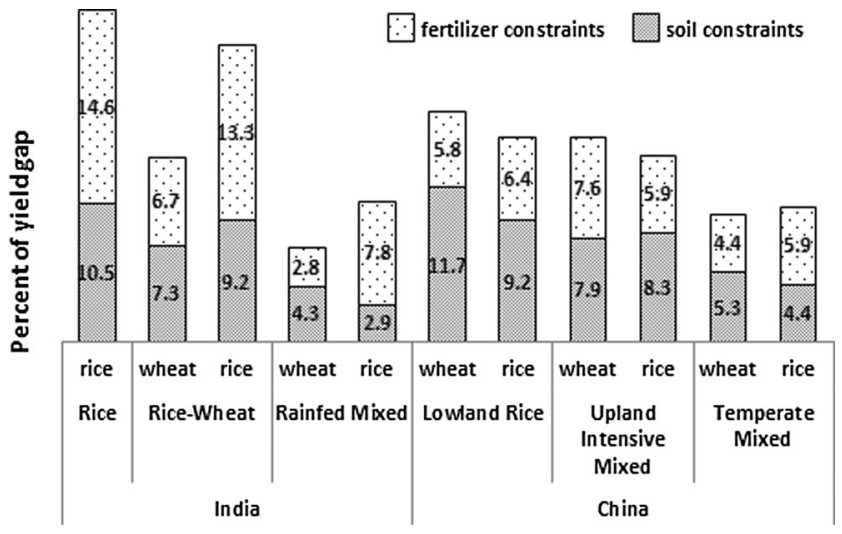

Fig. 4 Estimated yield losses associated with important soil and fertilizer constraints for wheat and rice in six farming systems in China and Indian sub-continent, 2008-09

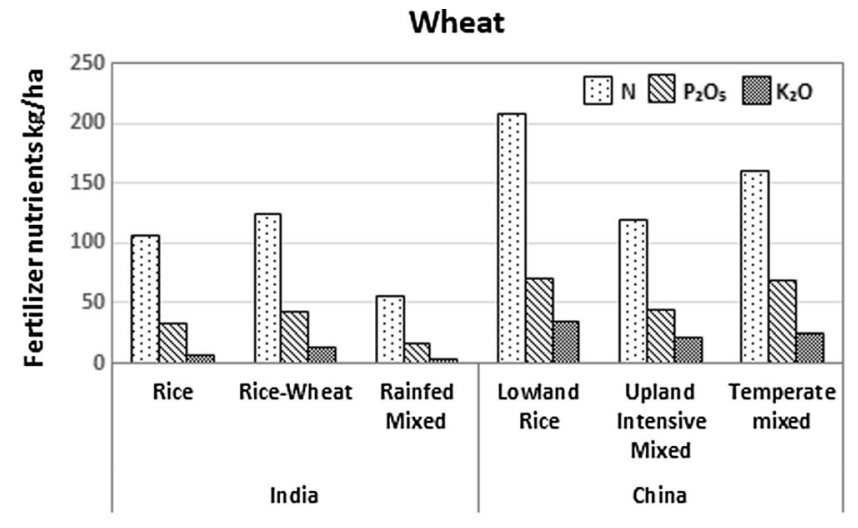

Rice

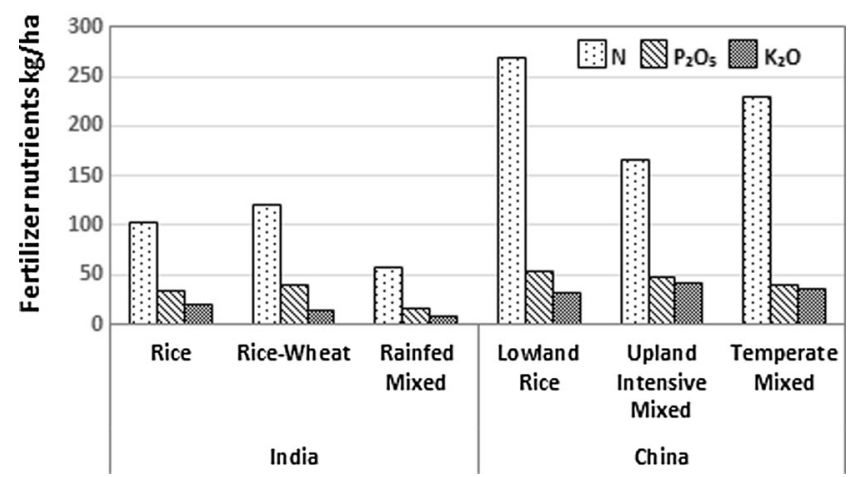

Fig. 5 Amounts of fertilizer nutrients $\left(\mathrm{kg} \mathrm{ha}^{-1}\right)$ reported applied to wheat and rice in cereal-based farming systems of India and China in 2000s (Source: FAO report 2005, Li et al. 2013) 